\title{
Article
}

\section{A Mixed-Mode Examination of the Teaching of Lead Climbing by Adventure Sports Coaches in the UK}

Collins, Loel and Collins, Dave

Available at http://clok.uclan.ac.uk/32050/

Collins, Loel ORCID: 0000-0002-7478-1140 and Collins, Dave (2020) A MixedMode Examination of the Teaching of Lead Climbing by Adventure Sports Coaches in the UK. Physical Education and Sport Pedagogy, 25 (5). pp. 478492. ISSN 1740-8989

It is advisable to refer to the publisher's version if you intend to cite from the work. http://dx.doi.org/10.1080/17408989.2020.1741538

For more information about UCLan's research in this area go to http://www.uclan.ac.uk/researchgroups/ and search for <name of research Group>.

For information about Research generally at UCLan please go to http://www.uclan.ac.uk/research/

All outputs in CLoK are protected by Intellectual Property Rights law, including Copyright law. Copyright, IPR and Moral Rights for the works on this site are retained by the individual authors and/or other copyright owners. Terms and conditions for use of this material are defined in the policies page.

\section{CLoK}

Central Lancashire online Knowledge www.clok.uclan.ac.uk

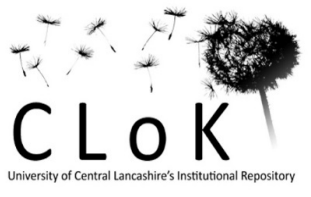


A Mixed-Mode Examination of the Teaching of Lead Climbing by Adventure Sports Coaches in the UK.

Loel Collins 1, 2 and Dave Collins 3, 4

1: Institute of Coaching and Performance, University of Central Lancashire

2: Plas y Brenin, National Outdoor Centre, Capel Curig, Conwy, LL24 OET

3: Moray House School of Education and Sport, University of Edinburgh

4: Grey Matters Performance Ltd.

*Corresponding Author: Loel Collins, loel.collins@pyb.co.uk 
Abstract

Background: We present a unique study of adventure sports coaches teaching lead climbing. Expanding existing work on judgement and decision making, we examine the coaching process and the decision making employed to manage the pedagogical and security needs of climbers when they are being introduced to lead climbing.

Research design and data collection: As part of a mixed approach, an Applied Cognitive Task Analysis was initially conducted on a small sample of expert coaches $(n=7)$ before a questionnaire was designed and administered with a larger sample $(n=53)$.

Findings: The study identifies that the tuition of lead climbing is built on nine core elements that form a shared mental model which in turn is individualised to meet the needs and demands of the individual learning to lead climb. The existence of this coherent shared mental model displays minor modifications to reflect the coach's own climbing background. More importantly, the existence of this shared mental model is derived from the instructors' own experiences of climbing and teaching lead climbing rather than any formalised training. In short, this model is actualised through an informal community of practice.

Conclusion: The implication for training instructors is that the skills of adapting these nine core aspects to meet individual needs should also be given due consideration alongside the technical skills of rope work and security. 
Keywords: Rock Climbing, Coaching, Mental Models, Community of practice 


\section{Introduction}

The teaching and coaching of lead climbing is a unique aspect of rock climbing tuition that presents specific challenges for the adventure sports coach. For the coaches teaching lead climbing, training has typically focused on the practical aspects of security for the lead climber and coach during the coaching rather than the pedagogical skills associated with developing the lead climber (Reeves 2010; Fyffe and Peter 1990; Pesterfield 2011). However, from a more general perspective, the development of skills required to teach lead climbing presents an excellent example of high-stakes decision making in a group of coaches that is not noted for the formal tuition of decision-making training (Collins, Carson, Amos \& Collins,2017).. Accordingly, this paper examines the cognitive loads, decisions and mental models associated with teaching lead climbing in a two-part mixed study. In doing so, the paper addresses several questions: (1) What is the process associated with the teaching of lead climbing? (2) What are the critical points of the cognitive processes associated with teaching lead climbing? (3) What is the extent and nature of coherence in any shared mental model between instructors teaching lead climbing? In the following section, we outline the nature of lead climbing, coaching in adventure sports and the potential challenges associated with teaching lead climbing.

\section{What is lead climbing?}

Lead climbing is the first climber's ascent of a route while trailing a rope that is managed by a second climber, the belayer (see Figure 1). As the lead climber ascends the route, the rope is 'run' through a series of anchors (runners). These runners are either pre-placed in the rock (e.g. expansion or epoxy bolts like in sports climbing) or, more usually, placed by the leader during the ascent (as in 'trad' climbing, see Reeves 
2010; Fyffe and Peter 1990; Pesterfield 2011). Should the leader fall, they pass the lastplaced anchor and, assuming this holds, the lead climber is held by the rope that is secured by the belayer (see also Reeves 2010; Fyffe and Peter 1990 for a fuller description).

In the traditional mode, lead climbing places a high demand on the lead. It requires the physical ability and technical skills to undertake the climb; the mental capacity to judge the difficulty of the climb against their climbing ability - both a priori and as the ascent is in progress - and finally, the mental and physical skills to utilize the rope to provide security and attach to and place runners in the rock (in case of 'trad' climbing). Additionally, the capacity to communicate with the belaying climber who manages the rope from below is also essential. As part of the climbing pair, the following climber requires the capacity to control, anticipate and secure the rope (to belay), the ability to anticipate the leader's actions and behaviours and to react to a potential fall.

Insert Figure 1 close to this point,

\section{Coaching in adventure sports}

Coaching adventure sports, such as climbing, in hyper-dynamic environments has been identified by Simon, Collins and Collins (2017) as complicated and messy. These researchers suggest that this is because of the constantly changing synergies between the individual, the environment and the goals of the process. We propose that anticipating, planning and coping within this messy hyper-dynamic context generates even higher cognitive loads in the form of acute and chronic stressors on the coach (Collins and Collins 2015, 2019). In this regard, the coach requires the capacity to 
anticipate and manage acute stresses caused by factors such as unexpected changes in conditions while balancing those with chronic stressors such as the need to anticipate the trajectory for the student's development. Thus, teaching lead climbing requires the coach to make a series of complex decisions, which must be monitored and adjusted, as appropriate, as the activity continues. Such decisions include, for example, appraising and anticipating an aspirant lead climber's physical and cognitive ability in response to the pressures of lead climbing (aka 'being on the sharp end' - Pesterfield 2011). These also include consideration of the belayer's ability to manage the rope, as this provides the security, the leader's choice of a suitable route, impact of conditions on the lead climber's capacity to learn and both climbers' comprehension of the situational demands.

\section{Challenges of teaching lead climbing}

Coaches of adventure sports demonstrate an ability to respond to and adapt through a series of nested, classic and naturalistic decision-making scenarios that reflect the situational demands of the activity, environment and participant (Collins and Collins 2016a, 2016b; Abraham and Collins 2011). The focus of the coaching process is a decision that balances the learning needs and security of the individual student - in short, a risk versus benefit decision (Collins and Collins 2013). The coach is required to be adaptive and flexible in response to these situational demands and constantly select the optimal approach to address those demands. Such an approach requires the coach to have a range of pedagogical and practical skills, together with a metacognitive capacity to synergise these factors effectively in order to keep the student safe while also ensuring that they learn.

Specifically, there is a need to address the emotional challenges of lead climbing (see Draper et al. 2008; Draper et al. 2010; Thatcher, Jones and Lavallee 2012) and to 
manipulate those emotions for optimum outcomes (see Rathschlag and Memmert 2015). In the lead climbing context, the dominant emotional concern is a fear of falling. Fear has multiple effects (Collins, Willmott and Collins 2018). It works (1) to discomfort and change the climbers' focus, making the lead climber dwell on and even rehearse, either overtly or covertly, the consequences of errors; 2) to increase the likelihood of emotional demands (MacPherson, Collins and Morriss 2008); (3) to disrupt the timing of and emphasis on a single aspect of movement such as a particular action required to ascend a problematic section of rock; and (4) as a chronic effect, causing the climber to struggle to control the intrusive thoughts of falling.

Consequently, the coach's fundamental decision is likely to be when to expose the potential lead climber to the full extent of the challenge and allow them to manage the risk of falling and any potential injury associated with falling. Given the complexity and multiplicity of issues, the coach's practice in this context seems ripe for further research. Consequently, this study examined the cognitive loads, decisions and mental models associated with teaching lead climbing.

\section{Method}

A mixed method approach was utilized (Teddlie and Tashakkori 2009). Part 1 reports an Applied Cognitive Task Analysis (ACTA) (Militello and Hutton 1998) with a group $(n=7)$ of highly qualified adventure sports coaches who regularly teach lead climbing. The ACTA was utilized to elicit the critical cognitive elements from those participants. These data were then used to directly inform the questionnaire (reported as Part 2) in an attempt to elicit the degree of coherence between the findings of the ACTA across a larger sample $(\mathrm{n}=53)$. 


\section{Part 1: Applied Cognitive Task Analysis}

\section{Participants}

To ensure a sufficient level of domain expertise, experience and inherent quality in terms of participants' self-reflective ability, purposive sampling was employed based on the following criteria: Participants $(n=7$; female $-n=2$ and male $-n=5)$ were coaches based in the United Kingdom $\left(M_{\text {age }}=33.5\right.$ years $)$ and were selected as per the following criteria: (1) a minimum of five years' coaching experience, since senior accreditation, as a mountaineering instructor or guide; (2) active engagement in teaching lead climbing; (3) to have been teaching lead climbing within the previous month and (4) willingness to discuss their professional practice. Steps were taken to ensure the anonymity of the participants, performers or other significant people involved in the study and guard against any potential deductive disclosure.

\section{Procedure}

Three stages of the ACTA (Militello and Hutton 1998) were applied (Table 1). The ACTA comprises a three-step process: (1) the task diagram with associated interview, (2) the knowledge audit and (3) a simulation interview with data synthesised using a cognitive demands table. Specifically, the ACTA procedure involved a partnership between interviewer and interviewee in an exploration of what information was influential in teaching lead climbing

Insert Table 1: Close to this point 
Task diagram. Participants were asked to consider a task diagram prior to the initial interview. They were asked to identify the three to six major steps involved in teaching lead climbing, the sequence in which the steps were to be carried out and those requiring greater cognitive effort.

Knowledge audit. The knowledge audit took the form of a semi-structured interview and aimed to identify how the coaches' expertise was used and to capture important aspects of this expertise. These included diagnosis and prediction, situational awareness and demands, adaptability and flexibility, perceptual skills, development of the 'tricks of the trade' and knowledge of when to apply them, and heuristics, improvisation, metacognition, recognition of anomalies and compensation for equipment limitations. The use of probes enabled a more in-depth examination of the nature of these skills, specific events and strategies. These probes were used to examine the cues and strategies of decision-making.

Simulation interviews. This stage of the interview focused more specifically on the coach's cognitions within the coaching process. Using an identical simulation scenario, the challenges faced by inexperienced teachers of lead climbing were presented verbally to each participant. The simulation responses were probed to expand the points raised in the knowledge audit.

A guide (Table 1) was constructed with questions influenced by the critical incident technique (Flanagan 1954), which acted as a 'knowledge elicitation strategy' (Flin, O'Connor and Crichton 2008, 222). The interviews allowed us to elicit key information and explore experiences in greater depth. Specifically, the process involved a partnership between interviewer and interviewee, the key element of which was an 
exploration of what information was influential when assessing a situation or selecting a particular course of action (Flin et al. 2008).

\section{Analysis}

After conducting these three stages of the ACTA, a cognitive demands table (Table 4) was used to analyse the data and focus the analysis on the research aims and objectives. The table provides a format that focuses analysis on the research aims by reviewing the common themes that emerge from the data derived from stages 1, 2 and 3 . We focused on difficult cognitive elements, the reasons for their difficulty, the anticipation employed in addressing these challenges (cues and strategies) and anticipated common errors. The table identifies common themes in the data, connecting information and relationships.

\section{Results}

\section{Task diagram}

Universally, the participants identified an open-ended four-stage linear process of increasingly focused planning that culminated in an individualised coaching process (Table 2). The initial stage harvested salient information regarding the environment, together with the climbers' levels of skills, both leader and belayer, and other characteristics. This enabled the coach to design a strawman plan of the initial interaction with the aspirant lead climber. The plan was explicitly created to be deconstructed as the outcome of a second stage became apparent. Stage 1 and 2 operated in a mesocycle, providing a framework to the start of the coaching process by incorporating the contextual and logistical demands. The second stage completed an audit of the quality and accuracy of the information gathered in stage 1 and was based 
on contextual observation of the conditions and the responses of the aspirant lead climbers in that context. This cycle, plan and audit re-plan process identified the actual start point of the coaching process and was repeated until a 'best fit' / risk versus benefit decision could be made within the contextual framework. The coaching interaction, stage 3 , was then designed as a microcycle that continually utilised nine common components. This adapted 'Ishikawa diagram' (Wong, 2011) was more consolidated than the strawman plan but retained a capacity for adaptation in response to changing environmental or student developments. An Ishikawa diagram is a pictorial representation of the components of a common phenomenon, lead climbing in this case. In this context, the factors have varied impacts on the phenomenon. The Ishikawa diagram (Fig 2) is drawn like a fishbone and helps identify the relationship between the components, which varied in significance depending on the situational demands. A continuous cycle of plan, do, observe, question [explicitly of the climber by the coach and implicitly of the coach by the coach (a metacognitive aspect)] and re-plan was then actualised" The proportion of focus on each of the nine components varied in response to the preceding cycles of observation and questioning.

\section{Knowledge audit}

The coaches drew on a range of knowledge sources, primarily derived from their experiences of learning lead climbing and being active lead climbers themselves, though none of them recalled ever being taught to lead climb in a formalised way. All of them had completed a 'traditional climbing apprenticeship', as one interviewee described. This apprenticeship involved a progression from mountain walking to mountaineering to rock climbing, a 'trad' apprenticeship. This differed from a 'sport' climbing apprenticeship that starts with indoor or sport climbing - an increasingly 
common approach. Implicit within this was a high degree of reflective practice, metacognitive capacity and emotional intelligence. The coaches had managed their own learning and constructed meaning based on their own reflection and interactions with their community of practice. Interview two said 'I try to solve the issue myself first by seeing what's worked before in similar situations, sometimes I'll run it past other instructors in the staff room if I'm really stuck'. The coaches did not articulate reflective practice as an explicit aspect of practice, seeing it instead as more a synergetic aspect of their adaptability. Interviewee four highlighted ' I don't reflect formally, I think about what I can do better next time if I encounter the same situation with a client but most of my thinking is solving the problem as it comes up and then realising what has and hasn't worked well' Thus, this reflection was inherently in-action and on action / in context. The coaches identified a limited range of specific technical requirements to safeguard themselves while coaching; these skills were adaptations of typical climbing skills such as those used in jumaring ${ }^{1}$ but also reflected highly specialist adaptations of those techniques in rope work.

\section{Simulation interview}

As a final part of the interview process, the participants were asked to imagine the problems an inexperienced coach may encounter when teaching lead climbing for the first time. The participating experts identified that the key challenges existed in stages one and four of the task diagram but the impact was apparent throughout the process $-\mathrm{a}$ ‘messy' (Collins, Simon and Carson 2019) problem of multiple inter-relating factors.

\footnotetext{
${ }^{1}$ Ascending a fixed rope using a pair of mechanical devices with a cam that grips the rope when weighted but can be freely moved upwards when unloaded.
} 
For example, in stage one, novices might overestimate the accuracy of the information gathered regarding the environment and the abilities of the climber or not place appropriate value or significance on particular aspects of that information (e.g. wind direction). Interviewee three highlighted 'some folks over estimate their own abilities, this can be really tricky until you've seen them' These assumptions may lead to heuristic bias in the decision-making process. Such misestimating might also lead to an undervaluing of stage two and consequently, poor venue selection that does not facilitate sufficient breadth and depth of activity to complete the audit effectively. This in turn makes the later stages weaker. As one interviewee described, one had to 'flexibly plan and go with the flow'

Additionally, novices tended to construct rigid plans too early and become emotionally attached to them. A second and third interviewee described this as 'over planning' and 'planning to death' respectively. This over planning compounded an inability to be responsive to changes in situational demands. Such a lack of consideration reflected a further heuristic bias and perhaps contributes to a decision-making paradox, common in other coaching contexts. The second interviewee expanded their comment '...the inexperienced coach seems to plan for all possibilities rather than the realistic ones, I guess that's because they have no idea of what's realistic'. The seventh interviewee described the outcome as 'paralysis by analysis'. In stages one and four, several interrelated factors such as situational awareness, sufficient practical, technical and pedagogical options, knowledge of factors that instigate needs for a change in approach and an acceptance of the need to be adaptable all coalesce in this coaching mess (Collins, Simon and Carson 2019). The fith interviewee suggested that 'just having the options isn't enough, the coach has to know why' 


\section{Cognitive demands table}

A series of acute loads were highest in stages 2 and 3 of the process. It is at this point that the potential discrepancies between the decisions made in stage 1 and the realities are most considerable and may have the most significant impact. A climber's misperception of their own climbing ability could lead to a poor route choice, for example, which increments key safety factors. Equally, selecting a route that may not engender the same psychological pressures as actual lead climbing may be insufficiently stimulating for the climber. The accuracy of the information on which the decisions have been made in stage 1 sits at the root of the processes' efficacy. However, the discrepancy between the climber's perception of their performance and the reality needs to be managed directly with the climber, which may be difficult as climbers appear to attach a great deal of importance to the self-perceived quality of their climbing ability. Despite these factors, however, stage 1 was reported as having a lower acute cognitive demand because the coach applied a set of conservative heuristics and drew on their experience in venue selection, i.e. selection of a venue that offered a diverse range of opportunities. The driver for the initial venue selection was diversity to enable as complete an audit as possible in stage 2 .

By contrast, chronic cognitive load was high in stages 1 and 4. As highlighted above, the cognitive loads in stage 1 are managed by the coach applying a range of conservative heuristics and a focus on diversity of activity at a given location. However, in stage 4, during the continual plan and re-plan of the coaching process, prioritising and drawing from a range of technical and pedagogical options generates a cognitive demand that runs throughout the process. Individually, the load is managed by anticipating a trajectory for the climber's development and working several stages ahead. This projection is, in turn, dependent on the coach knowing how the climber may react to a given approach or situation. In this respect, 
the coach is anticipating the lead climber's trajectory, rate and direction of development and response to the coaching. Thus, reflection on the experience of teaching lead climbing is required. Explicitly, the demands lay in identifying and prioritising from the nine critical aspects identified in stage 3 and modulating these in response to the demands of the situation and the needs of the aspirant climber. Thus, the chronic load was 'in action' and linked to the cyclical aspect of the coaching process highlighted in the task diagram earlier.

However, reflecting the non-generalisability of the ACTA and the responses in the knowledge audits and simulation interviews, a coherent view of the nine components identified in stage 3 could not be identified, since these components were more thematic aspects of the analysis in the cognitive task table. Consequently, in part two, we asked a larger sample of experts how they would prioritise the nine components.

\section{Part 2: Questionnaire}

\section{Participants}

To ensure a sufficient level of domain expertise, and inherent quality in terms of participants' experience and qualification, a self-selecting group of qualified mountaineering instructors and guides was invited to participate $(n=72)$. Participants $(n=53$; female $-n=12$ and male $\mathrm{n}=41$ ) self-selected and agreed to participate based on the following criteria: (1) holding a recognized award that qualified them to teach lead climbing, (2) being regularly engaged in teaching lead climbing and (3) being willing to be involved in the survey.

\section{Procedure}

The delegates were invited to take part in the study at a professional development conference for mountaineering instructors in the UK. Information was distributed throughout the 
conference. Participants could then approach the first author for a copy of the questionnaire (shown in Table 2), sign consent and ask any questions relating to the study. The questionnaire was then completed in the participant's own time during the conference and returned to the first author by the end of the conference. Clarification regarding any of the responses was agreed between the first author and participant on receipt of the questionnaire. Participants were asked to prioritize the nine critical factors identified in stage 3 (Ishikawa diagram) of the task demands (Table 1 and Figure 2) section of the ACTA (see Table 2).

Insert table 2 close to this point

\section{Results}

The survey was distributed to 72 respondents. Fifty-six consented, and responses were received (76\% response rate). Three surveys were incomplete and fell outside the criteria for completion (95\% completion rate). Reflecting on the recommendations of Norman (2010), the Likert values associated with the Factor variable were considered as parametric, and all analyses proceeded on this assumption. The analysis was completed using two mixed ANOVAs to systematically address the research questions.

A 3 X 9 (Qualification X-Factor) ANOVA with repeated measures on the second factor demonstrated a highly significant main effect for Factor but no significant effects for Qualification or the interaction. Accordingly, we focussed on the other 2 X 9 (Style XFactor) ANOVA with repeated measures on Factor. Once again, this yielded a significant main effect for Factor $[\mathrm{F}(8,384)=18.7, \mathrm{p}<.001]$ but also a significant Style $X$ Factor interaction $[\mathrm{F}(8,384)=1.97, \mathrm{p}<.05]$. A follow up to the significant main effect used Tukey's HSD tests with the Bonferroni adjustment. These results are shown in Table 3, with significant differences shown via Duncan's underlining method. 
Insert Table 3 close to this point

As shown in Table 4 the data clustered into three groups. The underlining method 'joins' variables that are not significantly different. Thus, the four highest-rated variables (PR, PA, QM and PP) were not significantly different from each other, but did form a group that was significantly different than the other five variables. As a contrast, at the other end of the table, IND, Learn, Pair and RW were not significantly different but only Pair and Lead after were significantly different from the middle cluster of Hol, RW and Learn.

Results underpinning the significant Style X Factor interaction were also followed up by use of Tukey's test. These data are presented in Table 4.

Insert Table 4 close to this point,

This test suggests that the interaction was mostly due to the more homogenous scoring by Style respondents. There were also differences in the order of values; however, none of these differences reached significance.

\section{General discussion}

\section{Individualization by structure or design?}

Individualization within the coaching process was a result of practicality, working with a single climber at a time while the other was belaying. The coaches recognized that individuals within each climbing pair might need different inputs to be able to lead climb. In this respect, the coach is managing multiple demands from a single performer but not differentiating coaching between different performers. It would seem logical then that the training focused on identification of the climbers need rather than differentiation of needs between the climbers themselves. 
The content, pace, and direction of the sessions reflected the pedagogical and developmental needs of that individual climber. However, a holistic mental template consisting of nine components was shared across different qualifications and experiences. This nine-component mental model (the Ishikawa plan) acted as a shared mental model for coaching rather than a technical template for performance. The significance of each of the nine components varied for the individual being coached. In this respect, the nine components act as themes and topics that can be combined in a myriad of combinations to meet the climbers' developmental needs.

\section{A shared adaptable mental model}

Current training programmes for coaches teaching lead climbing in the UK focus on the technical requirements for security of both the climbers and the coach. It is therefore surprising, but important, to find a high degree of coherence in the mental models that deal with how to teach lead climbing. A small degree of variation reflects the antecedents of each coach. Those who came from a 'trad' climbing background and those who had a sports climbing background prioritised differing aspects of the nine-part mental model. In this respect, the mental model was individualised to the coach as well as to the climber. This difference possibly reflects the recent 'sportification' of climbing in the UK, with increased access to manufactured climbing facilities such as climbing walls and the development of climbing as a competitive sport (cf. inclusion in the Tokyo Olympics) in which selection and placement of 'runners', for instance, is not a factor. The coaches from the 'trad' background focused on these skills associated with choice, selection and placement of climbing protection while lead climbing. This may reflect two factors: 1) the UK climbing culture that has a historical focus on 'trad' climbing and the historic link between mountaineering instructional 
qualification and lead climbing tuition ${ }^{2}$ and 2) the safety imperative in 'trad' climbing. The coaches with a sport climbing focus attended more to the rope work associated with passing the rope through the runners as part of the lead climb - an aspect of climbing fluency that presumably links to the speed aspect of competitive climbing or the flow of movement over the rock. On sport climbs, the first ascensionist places protective bolts in an optimal position (bolts can be in any solid rock), and they remain in position. In 'trad' climbing, protection is constrained by the availability of cracks and other rock features. Protection placement in trad climbing is closely linked with the lead climber's need to perceive and respond to the risk associated with lead climbing - a situational awareness and response to the demands of the climb and conditions. Consequently, the focus lay more towards situational awareness and protection placement - in the form of a risk versus benefit assessment - for those coaches from a 'trad background'. The manufactured and engineered environments of climbing walls and managed protection in sport climbing routes negates the need for sport climbers to pay attention to protection placement, since the effectiveness of protection is dependant on engineering and the belayer rather than on the choice of anchors. In both the 'trad' and sport genres, the belayers' skills remain the paramount safety mechanism, and absolute confidence in the partnering climber's ability to belay, anticipate movements and respond to a fall is critical.

\section{Introducing lead climbing}

The coherence of the mental model is supported by a range of pedagogical strategies and technical approaches.

\footnotetext{
${ }^{2}$ Until 2012, to teach, lead climbing instructors also had to be qualified mountain leaders.
} 


\section{Pedagogical strategies}

Notable amongst these are the ones that synergistically develop the practical and cognitive skills of the lead climber. These approaches reflect the nature of lead climbing as both a cognitive and physical activity and challenge notions of skill acquisition that do not incorporate this explicit cognitive aspect of performance (cf. Fitts and Posner 1967; Dreyfus and Dreyfus, 1980; Christian and Sutton 2016). The coaches described a range of approaches that retained this synergetic focus, including notions of cognitive apprenticeship (Collins, Brown and Newman 1988), together with a range of think-aloud processes that were retrospective, interactive and classical (Xiang and Rau, 2019). Moreover, a concurrent commentary by the coach and lead climber was widely used. Some of the decision training tools identified by Vickers (2007) are also employed, though these are not explicitly articulated and had practical limitations (the use of video, for example, is practically difficult on a multi-pitch route, but not impossible).

The coaches explicitly managed the constraints of the learning experience. The breadth of factors that needed to be considered by the climber and coach necessitated a focus on reducing overload resulting from too much input. The constraints were managed in a nuanced manner, so as not to replicate the 'sharp end' experience but more to ensure a cognitive capacity to enable learning in a realistic enough context - a recognition of learning as a cognitive process. Rather, the approaches had evolved via the coaches' own reflective practices, observation of the climber's responses to the environment and explicit sharing of their experiences with their community of practice. A hypothesis construction, testing and adaptation process at a macro and micro level formed the basis of the process. 


\section{Technical approaches}

Several techniques for direct and close supervision of the clients while leading under instruction are unique to the teaching of lead climbing. Thus, they currently form the basis of formalised training. However, the coaches referred to these techniques in different terms, suggesting a degree of isolation between different participants; a common language may be necessary in the training and refinement of the coaches to ease communication (cf. the important precursors of an effective CoP - Stoszkowski and Collins 2012). More importantly, however, this difference in terminology does not appear to have hindered the development of a shared mental model of a lead climber between coaches.

Rope work techniques were modified to meet the needs of the coach in order to safeguard themselves and the aspirant lead climber. Only one coach reported having to step in - by securing an aspirant lead climber - to safeguard, suggesting that the coaches were making effective judgements a priori with respect to the difficulty and nature of the climb. This would suggest a refined judgment of the essential level of activity and a practical manifestation of the shared mental model highlighted earlier.

As a result, a small selection of specific rope techniques emerged, unique to safeguarding the students while lead climbing. For example, a lead climber may be safeguarded using a rope from above while practicing the mechanics of managing the rope and anchors using a trailing rope in a simulated lead (see photo 1). As a consequence, the climber is belayed both from above and below. The simulated lead belayer learnt about paying out rope and anticipating the lead climber's movement while the lead climber learnt about anchor selection or placement and rope work. Then, the coach could not only provide feedback to both individuals with respect to their roles but also coach the pair in aspects of teamwork and communication, with the top roping climber providing ultimate security. These core technical 
components were modified in response to the students' needs and rate of development until a point was reached at which the coaches relied completely on the lead climber's lower belayer to provide security in the form of gear placement. The decision to expose the student to the 'sharp end' was based on the belayers' and climbers' skill levels as a pair.

The coaches all retained a holistic view of the lead and second climbers. This approach moved beyond merely being competent with each of the components and examined the climbers' capacity to integrate the components in a coherent manner. One of the coaches in Part 1 stated, 'It's about the sum of the partnership being greater than the value of the individual parts, especially if they're heading off on their own afterwards'. This need for resilience appeared to be an implicit acknowledgement of the 'wicked' nature of the challenge, where strengths in one aspect may be balanced against weaknesses in others. The weaknesses and explicit interaction of the component parts formed the focus of the coaching process.

The coaches made explicit judgments regarding the aspirant lead climber's skill levels in three technical aspects that all related to the potential of falling while lead climbing. First was the fluency of movement over the rock while using climbing ability to avoid any potential fall; this observation focused on fluency of climbing rather than on the difficulty. 'A route can always be selected that is within the ability of the climber,' observed one coach. 'However rushed or nervous movements can lead to a fall'. Second, rope handling and rope management, and third, placing and utilising protection were also ascertained. In these aspects, the coaches considered the cognitive load for the aspirant lead climber, wanting a high degree of autonomy and robustness in the execution of the task. It must be noted that this did not necessitate a particular standard of performance (climbing a particular grade of 
route) but more of a focus on the fluency of movement, on the process rather than the outcome.

\section{Conclusion}

In this study, we have provided a useful and strong consensus on how lead climbing may best be taught. We trust that this will be actively applied by the climbing community who are understandably voracious in their pursuit of better and safer practice.

We would also highlight the study's potential contribution to the wider coaching literature. It is important to note how strong a coherence has emerged in this high-stakes, specialist area, despite the absence of formal training courses that address the pedagogical considerations of the process. We would highlight three elements of the climbing environment which, we feel justified in claiming, may have influenced this consensus:

First is the tight social nature of instructors at this level, which has led to considerable informal discussion and debate on the process itself. In keeping with the suggestions of Stoszkowski and Collins (2012), coaching has a considerable social component, which participants in Part 1 of the study highlighted as an important feature of their coaching environment (cf. Collins and Collins 2015). We suggest that this aspect also led to the development and transmission of a strong shared mental model that was clearly apparent across all participants. It was also clear that this model had been developed informally, given the dearth of explicit teaching of the pedagogical aspect in relevant courses and the relative spread of technical terminology, which was apparent among the study's participants. Finally, and despite the 'trad' versus sport split, it was clear that all participants were significantly influenced in their coaching decision making by their own personal experiences as climbers (most explicitly supported in Part 1). Taken together, we would suggest that this highlights some important material for coaching educators, stressing the need for them to tap into and 
exploit the social milieu of the particular sport in which they are working. This might also offer some relevant guidance for national sports coaching organisations, suggesting that they too can make use of coaches' social experiences as a both touchstone (where content may come from) and driver (how ideas can best be spread).

\section{References}

Abraham, A., and D. Collins. 2011. "Taking the Next Step: Ways Forwards for Coaching Science. Quest 63: 366-384. http://dx.doi.org/10.1080/00336297.2011.10483687

Christian, W. D., and J. Sutton. 2016. "Cognition in Skilled Action: Meshed Control and the Varieties of Skill Experience.” Mind \& Language 31(1):37-66.

Collins, L., Carson, H. J. Amos P. \& Collins D.(2017). Examining the perceived value of professional judgement and decision-making in mountain leaders in the UK: a mixedmethods investigation. http://doi.org/10.1080/14729679.2017.1378584

Collins, L., and D. Collins. 2013. "Decision Making and Risk Management in Adventure Sports Coaching." Quest 65(1): 72-82.

Collins, L., and D. Collins. 2015. "The Adventure Sports Coach.” In Adventure Sports Coaching, edited by M. Berry, J. Lomax, and C. Hodgson, 5-23. Oxon: Routledge.

Collins, L., and D. Collins. 2016a. "The Foci of In-action Professional Judgment and Decision-Making in High-Level Adventure Sports Coaching Practice," Journal of Adventure Education and Outdoor Learning. 17:2,122-

132doi:10.1080/14729679.2016.1227717

Collins, L., and D. Collins. 2016b. "Professional Judgment and Decision Making in the Planning Process of High Level Adventure Sports Coaching Practice.” Journal of Adventure Education and Outdoor Learning. 16:3, 256-268 .doi.org/10.1080/14729679.2016.1162182

Collins, A., J. S. Brown, and S. E. Newman. 1988. "Cognitive Apprenticeship, Teaching the Craft of Reading, Writing and Mathematics" The Journal of Philosophy for Children 8(1): 2-10. doi: 10.5840/thinking 19888129 
Collins, D, T. Willmott, and L. Collins. 2018. "Periodisation and Self-Regulation in Action Sports: Coping with the Emotional Load.” Frontiers in Psychology. 8:1652 doi:10.3389/fpsyg.2018.01652

Collins, L., S. Simon, and H. J. Carson. 2019. "Para-adventure: A Hyper-Dynamic Problem for the Inclusive Coach." Sport in Society 22(7):1165-1182. doi: $10.1080 / 17430437.2018 .1504776$

Draper, N., G. A. Jones, S. Fryer, and C. Hodgson. 2010. "Physiological and Psychological Responses to Lead and Top Rope Climbing for Intermediate Rock Climbers." European Journal of Sports Science. 10 (1). pp. 13-20.

Draper, N., G. A. Jones, S. Fryer, C. Hodgson and Blackwell, G. 2008. "Effect of an OnSight Lead on the Physiological and Psychological Responses to Rock Climbing." Journal of Sports Science and Medicine. 7,492-498

Dreyfus, S. E., and H. L. Dreyfus. 1980. "A Five-Stage Model of the Mental Activities Involved in Directed Skill Acquisition". Washington, DC: Storming media retrieved Nov 25, 2019

Fitts, P. M and M. I. Posner. 1967. Human Performance. Belmont, CA: Brookes/Cole. ,Taylor \& Francis Group

Fyffe, A., and I. Peter. 1990. The Handbook of Climbing. London: Stephen Green Press.

Ji, X and P. P. Rau. 2019. A Comparison of Three Think-Aloud Protocols Used to Evaluate a Voice Intelligent Agent that Expresses Emotions. 38:4, 1-9 doi.org/10.1080/0144929X.2018.1535621

MacPherson, A., D. Collins, and C. Morriss. 2008. "Is What You Think What You Get? Optimizing Mental Focus for Technical Performance.” The Sport Psychologist 22(3): 288-303. doi: https://doi.org/10.1123/tsp.22.3.288

Militelo, L. G., and R. J. B. Hutton. 1998. “Applied Cognitive Task Analysis (ACTA): A Practitioner's Toolkit for Understanding Cognitive Task Demands.” Ergonomics, 41(11): 1618-1641.

Norman, G. 2010. Likert Scales, Levels of Measurement and the "laws" of Statistics. Advances in Health Sciences Education theory and Practice 15(5): 625-632. Doi:10.1007/s10459-010-9222-y

Pesterfield, H. 2011. Traditional Lead Climbing: A Rock Climbers Guide to Taking The Sharp End of the Rope, 2nd edition. Birmingham AL: Wilderness Press. 
Rathschlag, M and Memmert. D. 2015. "Self-Generated Emotions and their Influence on Sprint Performance: An Investigation of Happiness and Anxiety." Journal of Applied Sport Psychology 27(2), 186-199. doi: 10.1080/10413200.2014.974783

Reeves, M. 2010. How to Climb Harder. Bethesda, UK: Pesda Press.

Simon, S., L. Collins, and D. Collins. 2017. "Observational Heuristics in a Group of High Level Paddle Sports Coaches.” International Sport Coaching Journal, 4, 235-245. doi.org/10.1123/iscj.2017-0012

Stoszkowski, J. and D. Collins. 2012. "Communities of Practice, Social Learning and Networks: Exploiting the Social Side of Coach Development." Sport, Education and Society. 19:6, 1-16. doi:10.1080/13573322.2012.692671

Teddlie, C., and A. Tashakkori. 2009. Foundations of Mixed Methods Research; integrating Quantitative and Qualitative Approaches in the Social and Behavioural Sciences. California: Sage.

Thatcher, J., M. Jones, and D. Lavallee. 2012. Coping and Emotion in Sport: Future Directions. In Coping and Emotion in Sport, edited by D. Lavallee, J. Thatcher, and M. Jones, 271-278. New York: Nova Science.

Vickers, J. N. 2007. Perception, Cognition, Decision Training: The Quiet Eye in Action. Champaign, IL: Human Kinetics.

Wong, K, C. (2011) Using an Ishikawa diagram as a tool to assist memory and retrieval of relevant medical cases from the medical literature, Journal of Medical Case Reports 5, 120. https://doi.org/10.1186/1752-1947-5-120 


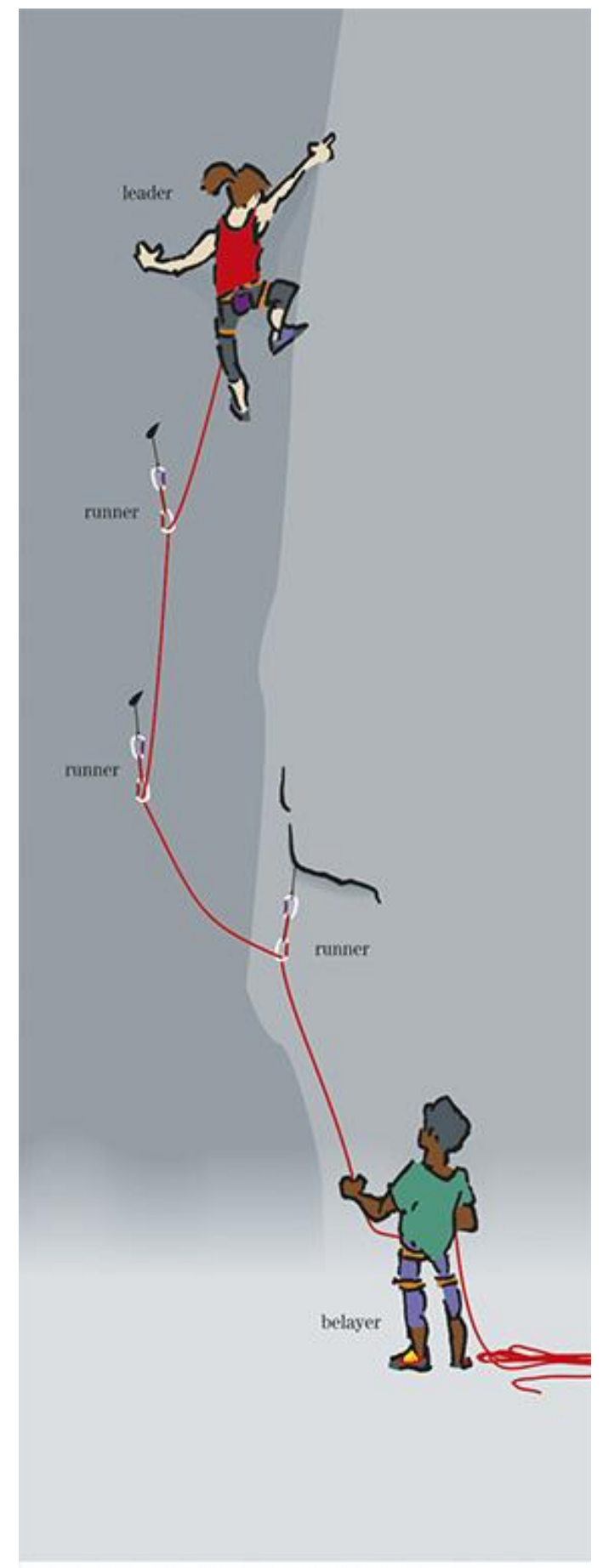

Ellustration from 'Rock Climbing' O MTUKVG 2015

Figure 1: Lead climbing, with permission from Mountain Training UK. 


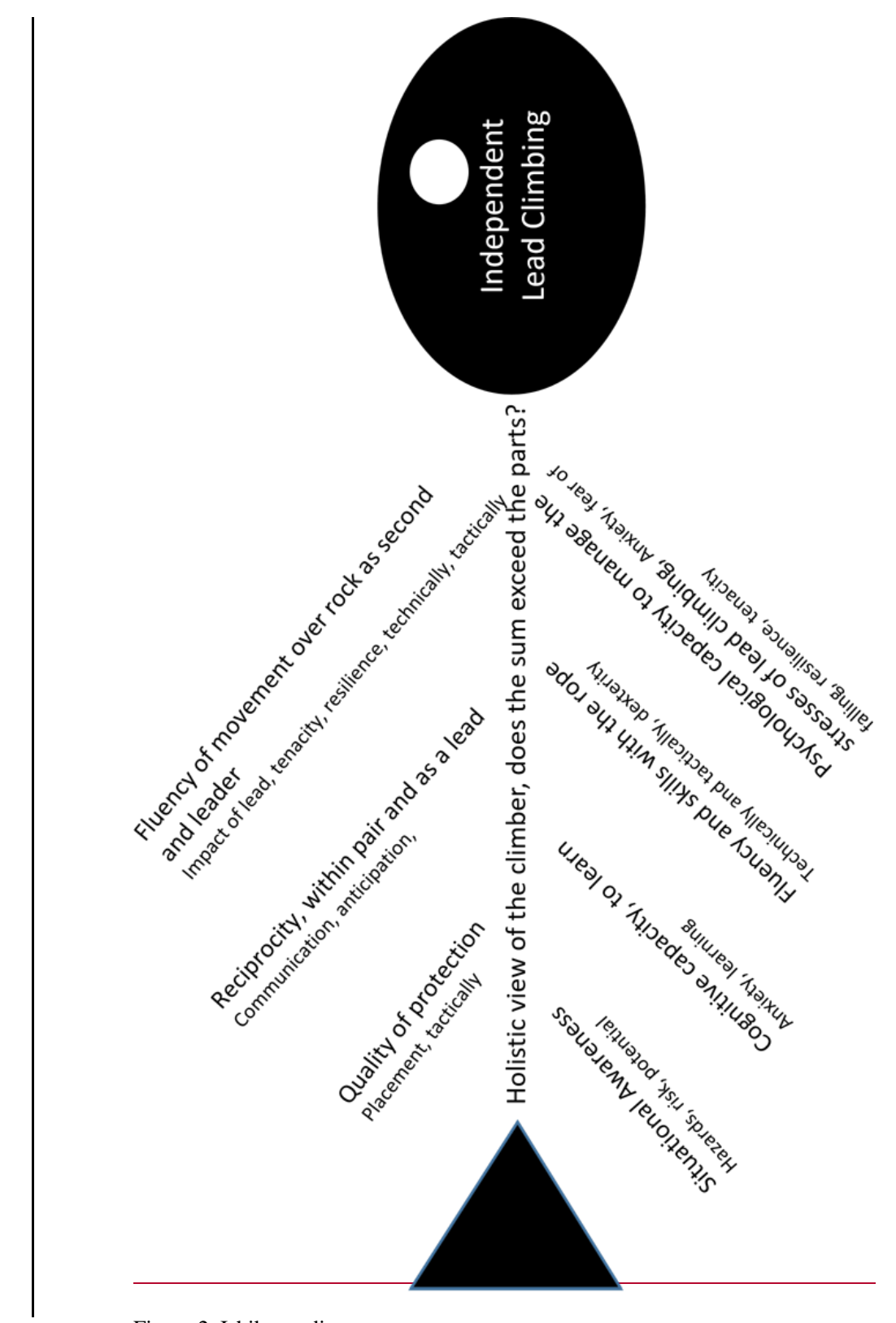

Figure 2, Ishikawa diagram 


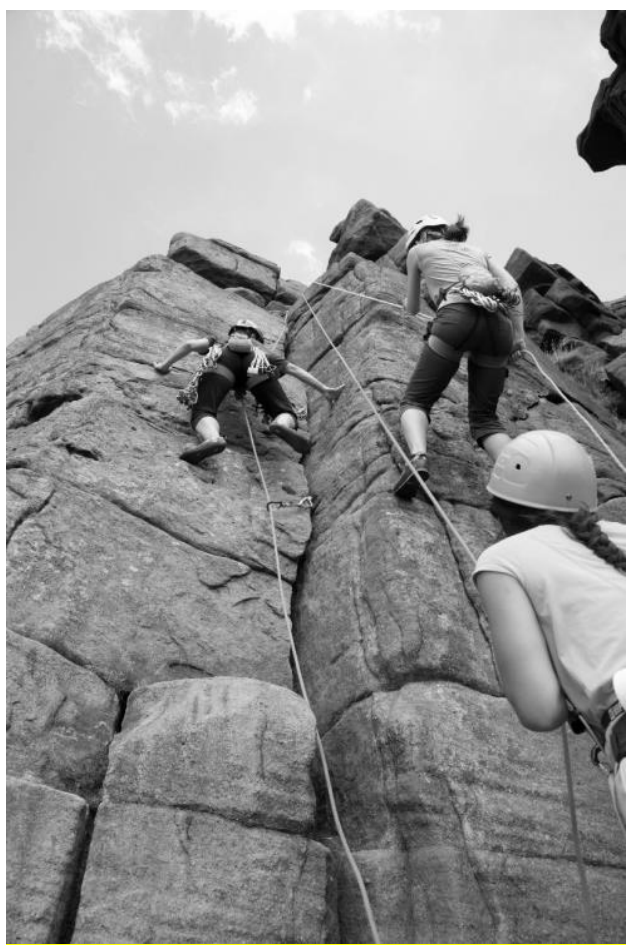

Figure 3; 'Ghost roping'; The lead climber is safeguarded above by a top rope (solid line) and from below with the simulated lead rope (dashed line), while also directly supervised by the coach. Anchors can be preplaced if rope work in a focus, or can be placed by the lead climber if anchors are the focus. 


\begin{tabular}{|c|c|c|}
\hline Table 1: Applied Cognitive Task Analysis content, prompts and stimuli & Prompts & Interviewing notes \\
\hline Can you break this task down into more than 3 , but less than 6 steps? & What are the key elements? & Draw it? \\
\hline $\begin{array}{l}\text { Of the steps you have just identified which require difficult cognitive skills or decisions on } \\
\text { your part? }\end{array}$ & $\begin{array}{l}\text { What are they? } \\
\text { Why Difficult? }\end{array}$ & $\begin{array}{l}\text { Highlight } \\
\text { Articulate, field notes }\end{array}$ \\
\hline \multicolumn{3}{|l|}{ Knowledge Audit. } \\
\hline Have you had experiences where part of this situation just jumped out at you? & $\begin{array}{l}\text { Cues? } \\
\text { What? } \\
\text { When? } \\
\text { How? }\end{array}$ & Noticing \\
\hline $\begin{array}{l}\text { Are there ways of working smarter or accomplishing more with less-that you have found } \\
\text { especially useful? }\end{array}$ & $\begin{array}{l}\text { Heuristics } \\
\text { Improvisation } \\
\text { Tricks of the trade } \\
\text { Contextual practices } \\
\text { Key indicators/ observations }\end{array}$ & Job Smarts \\
\hline $\begin{array}{l}\text { Can you think of an example when you have improvised or noticed an opportunity to do } \\
\text { something better? }\end{array}$ & $\begin{array}{l}\text { Improvisation } \\
\text { Adaptation } \\
\text { Flexibility } \\
\text { Cues } \\
\text { Triggers } \\
\text { Use/ context } \\
\end{array}$ & $\begin{array}{l}\text { Opportunities } \\
\text { Improvisation }\end{array}$ \\
\hline $\begin{array}{l}\text { Can you think of a time when you realised that you would need to change the way you were } \\
\text { working in order to get the job done? }\end{array}$ & $\begin{array}{l}\text { Self aware } \\
\text { EI } \\
\text { CI } \\
\text { Of own DM } \\
\end{array}$ & Metacognition \\
\hline $\begin{array}{l}\text { Can you describe an instance when you spotted a deviation from the norm, or knew } \\
\text { something was amiss? }\end{array}$ & $\begin{array}{l}\text { Atypical } \\
\text { Unusual } \\
\text { exceptional }\end{array}$ & Anomalies \\
\hline $\begin{array}{l}\text { Have there been times when the events pointed in one direction, but your judgement told } \\
\text { you to do something else? Or when you had to rely on experience to avoid being led astray? }\end{array}$ & $\begin{array}{l}\text { Nature of that experience } \\
\text { How long? } \\
\text { Where? } \\
\text { What? } \\
\text { Gut feel/ intuition }\end{array}$ & \\
\hline $\begin{array}{l}\text { Simulation Interview: } \\
\text { What are the common 'pit falls' for instructors new to teaching lead climbing }\end{array}$ & $\begin{array}{l}\text { Commonalities in process } \\
\text { Differences in process } \\
\text { ( not just technical, context) }\end{array}$ & \\
\hline
\end{tabular}




\begin{tabular}{|c|c|c|c|}
\hline Stage 1: Strawman plan & Stage 2: Audit & Stage 3: Ishikawa plan & Stage 4: Application of Plan \\
\hline $\begin{array}{l}\text { Creation of a 'Strawman plan' that } \\
\text { includes a suitable location that } \\
\text { offers a broad range of } \\
\text { opportunities for stage } 2\end{array}$ & $\begin{array}{l}\text { Verifying, checking and } \\
\text { challenge to the strawman } \\
\text { plan }\end{array}$ & $\begin{array}{l}\text { Deconstructing the strawman plan and re } \\
\text { constructing a 'fishbone plan' }\end{array}$ & $\begin{array}{l}\text { Adaptive application of Ishikawa } \\
\text { plan }\end{array}$ \\
\hline $\begin{array}{l}\text { Harvesting appropriate and } \\
\text { relevant information } \\
\text { Environmental } \\
\text { - Weather } \\
\text { - Conditions } \\
\text { Participant } \\
\text { - Perceived ability and } \\
\text { - } \quad \text { Motivation to lead climb } \\
\text { - Situational awareness } \\
\text { - Relationship with partner } \\
\text { - Comprehension of } \\
\text { - climbing } \\
\text { Personality, temperament }\end{array}$ & $\begin{array}{l}\text { The audit and re plan. } \\
\text { Observation in a realistic } \\
\text { context, questioning to } \\
\text { elicit detail } \\
\text { - Quality and accuracy } \\
\text { of information } \\
\text { - Any new information } \\
\text { - Filling in any gaps } \\
\text { - 'Putting colour in the } \\
\text { image'. ASC1 } \\
\text { - 'Getting an honest } \\
\text { picture' ASC } 4\end{array}$ & $\begin{array}{l}\text { The Ishikawa plan with nine consistent aspects ( see } \\
\text { fig 2) } \\
\text { 1. Overarching, a holistic view of a lead } \\
\text { climber, is the sum of the components } \\
\text { greater than that of the parts? The strength } \\
\text { and durability of the interactions of the } \\
\text { parts, that are; } \\
\text { 2. Movement over the rock } \\
\text { 3. Rope-work skills } \\
\text { 4. Protection placement } \\
\text { 5. Psychological abilities to be at 'the } \\
\text { sharp end' } \\
\text { 6. Capacity to learn while at 'the sharp } \\
\text { end'. } \\
\text { 7. Perceptions of the risks (Situational } \\
\text { 8. The climbers ability as part of the } \\
\text { climbing pair ( reciprocity) } \\
\text { 9. The climbers ability to lead climb } \\
\text { independently }\end{array}$ & $\begin{array}{l}\text { From the nine components the } \\
\text { significance and priority is } \\
\text { individualised. Reflecting the } \\
\text { client's actual abilities, their } \\
\text { strengths and weaknesses. Focused } \\
\text { attention is on strengthening the } \\
\text { interaction of those consonants as } \\
\text { well as the component parts acting } \\
\text { as a multiplier }\end{array}$ \\
\hline
\end{tabular}


Mean

SD

\begin{tabular}{l|l|l|l|l}
\hline Perc Risk & 2.30 & 1.810 & & \\
\hline Psych & 3.36 & 2.078 & & \\
\hline Qual & 4.22 & 2.460 & & \\
\hline Gear & 4.30 & 1.843 & & \\
\hline Holistic & 4.76 & 2.904 & & \\
\hline Rope & 5.70 & 1.555 & & \\
\hline Learn & 5.80 & 2.010 & & \\
\hline Pair & 6.84 & 1.833 & & \\
\hline Lead after & 7.68 & 1.609 & & \\
\hline
\end{tabular}

Table 3: Descriptive and significant differences for Factor 


\begin{tabular}{lr|r|r|r|r|r|r} 
& \multicolumn{2}{c}{ Traditional } & \multicolumn{3}{c}{ Sport } \\
& N & Mean & SD & & N & Mean & \multicolumn{1}{c}{ SD } \\
\hline Perc Risk & 39 & 2.36 & 1.828 & Perc Risk & 11 & 2.09 & 1.814 \\
\hline Psych & 39 & 3.41 & 2.048 & Psych & 11 & 3.18 & 2.272 \\
\hline Qual & 39 & 3.82 & 2.088 & Gear & 11 & 4.45 & 2.544 \\
\hline Gear & 39 & 4.26 & 1.634 & Rope & 11 & 5.09 & 1.221 \\
\hline Holistic & 39 & 4.64 & 3.013 & Holistic & 11 & 5.18 & 2.562 \\
\hline Learn & 39 & 5.56 & 2.062 & Qual & 11 & 5.64 & 3.202 \\
\hline Rope & 39 & 5.87 & 1.609 & Pair & 11 & 6.27 & 1.954 \\
\hline Pair & 39 & 7.00 & 1.792 & Lead after & 11 & 6.45 & 2.339 \\
\hline Lead after & 39 & 8.03 & 1.158 & Learn & 11 & 6.64 & 1.629 \\
\hline
\end{tabular}

Table 4 Descriptives for Factors split by Style 